\title{
Non-pharmacological intervention for gastro-oesophageal reflux disease in primary care
}

\author{
Lesley B Dibley, Christine Norton and Roger Jones
}

\begin{abstract}
Background

Up to $50 \%$ of patients with gastro-oesophageal reflux disease (GORD) have persistent symptoms despite taking proton pump inhibitors (PPIs) regularly. Lifestyle advice is available to patients, but no previous UK study has tested a behavioural change intervention to help patients self-manage their symptoms.
\end{abstract}

Aim

To determine whether a primary care, nurse-led intervention to address behaviours that promote GORD symptoms results in symptom improvement, an increased sense of control, and a reduced requirement for prescribed medication.

Design of study

A group intervention focusing on diet and stress was delivered to patients with reflux symptoms, recruited in rural general practices.

Setting

General practice in England.

Method

Forty-two subjects (male 19, female 23) aged 31-86 years took part. Pre- and post-intervention data were gathered using the Brief Illness Perception Questionnaire (BIPQ), the GORD Impact Scale (GIS), and the Hospital Anxiety and Depression Scale (HAD).

Results

There was a significant improvement (BIPQ $P<0.001$, GIS $P=0.008) 3$ months after the intervention. There was no reduction in PPI use or change in HAD score. The greatest improvements were demonstrated in domains measuring the patient's sense of control, perception of symptoms, and understanding of reflux. Patients reported benefits including understanding relevant anatomy and physiology, learning behavioural techniques to change eating patterns and manage stress, identifying actual and potential triggers, and developing and executing action plans.

\section{Conclusion}

An education programme for GORD enhances selfmanagement, brings perceived symptom improvement, and promotes a sense of control at 3 months. This type of behavioural intervention, alongside medical management, could improve symptom control for reflux patients with refractory symptoms and should be the subject of a controlled trial.

\section{Keywords}

Gastro-oesophageal reflux disease; patient education; primary care; self-management.

\section{INTRODUCTION}

Gastro-oesophageal reflux disease (GORD) is a common cause of morbidity in the western world, affecting between $20 \%$ and $40 \%$ of the population. ${ }^{1}$ Proton pump inhibitors (PPIs) are usually effective, although estimates indicate that up to $50 \%$ of patients have refractory GORD symptoms despite regular PPI use. ${ }^{2}$ UK PPI prescribing has risen from approximately 29 million prescriptions in 2007, to 32 million in 2008. Costs are steady at an average of $£ 220$ million per year. ${ }^{3,4}$ Research and expert opinion has informed effective prescribing patterns, ${ }^{5}$ urged the need for regular review, ${ }^{6}$ and challenged the longterm prescribing of PPIs. ${ }^{7}$ Experimental studies have attempted to determine factors that exacerbate GORD symptoms, while population studies have explored socioeconomic and emotional issues that may influence symptom experience. ${ }^{8}$ Current advice is that more than one approach may be needed to treat GORD, 9 but the potential for lifestyle management as an effective companion or alternative to PPIs has been under-researched. Guidelines that do mention lifestyle management offer limited guidance and tend to focus on medical and surgical techniques to control GORD

LB Dibley, MPhil, RN, research fellow, Faculty of Society and Health, Bucks New University, Uxbridge. C Norton, PhD, MA, $R N$, professor of clinical nursing innovation, Faculty of Society and Health, Bucks New University, Uxbridge and Imperial College Healthcare NHS Trust, London. $\boldsymbol{R}$ Jones, DM, FRCGP, FMedSci, emeritus professor of general practice, Department of General Practice and Primary Care, King's College London.

Address for correspondence

Lesley Dibley, Faculty of Society and Health, Bucks New

University, 106 Oxford Road, Uxbridge, Middlesex.

E-mail: lesley.dibley@bucks.ac.uk

Submitted: 17 December 2009; Editor's response: 9

February 2010; final acceptance: 4 June 2010.

(-British Journal of General Practice.

This is the full-length article (published online 29 November 2010) of an abridged version published in print. Cite this article as: Br J Gen Pract 2010; DOI: 10.3399/bjgp10X544050. 
symptoms. ${ }^{10}$ No previous UK study has used behavioural change interventions to help patients self-manage their symptoms.

Self-management has proved effective in other chronic conditions. ${ }^{11}$ A range of non-pharmacological interventions are beneficial in several other gastrointestinal disorders, including irritable bowel syndrome (IBS). ${ }^{12,13}$ The effect size of such interventions is frequently comparable to or exceeds that of some pharmacological interventions alone. For example, a cognitive behavioural therapy trial for IBS substantially improved symptoms and quality of life. ${ }^{14}$ The effectiveness of an education intervention for GORD is unknown, as no previous study has evaluated this.

\section{METHOD}

A two-stage mixed methods study was designed to develop, deliver, and evaluate an education programme for patients with reflux disease. Patients were recruited from general practices in a rural county in England. Practice administrative staff conducted database searches to identify those fitting the inclusion and exclusion criteria. Patients were included if they were $>18$ years of age, had a diagnosis of reflux with or without endoscopy evidence, and were taking long-term PPIs (defined as monthly repeat prescriptions for at least 6 months within the previous year). Patients were excluded if they had significant additional physical morbidity or the GP advised against involvement. A total of 669 patients were identified and invited to participate in the study.

\section{Intervention development stage (stage 1)}

One hundred and seventy-nine of the original 669 patients responded, expressing an interest to take part in stage 1 , or 2 , or both stages of the study. Twenty-three patients were sampled, (12 women, 11 men, age range $31-86$ years, representative of the demographic spread of the responder group) to participate in semi-structured interviews. Using a schedule developed from the published evidence, patients were interviewed in their homes by the lead author, about aspects of their reflux that caused most concern, the influence of lifestyle including diet, alcohol, smoking, activity, posture, and dinner to bed time, and the problems they experienced in managing their symptoms. It was confirmed that daily living patterns do appear to affect reflux symptoms, combining in complex and distinctive patterns for each GORD patient. Where patients are aware of behaviours that may exacerbate their symptoms, they are often unable to make changes because they do not know how to. This development stage is reported elsewhere. ${ }^{15}$

\section{How this fits in}

Current advice suggests that multiple approaches may be needed to treat gastrooesophageal reflux disease (GORD), but the potential for lifestyle management as an addition or alternative to proton pump inhibitor (PPI) use has been under-

researched. Recommendations that mention lifestyle management offer limited guidance and tend to focus on medical and surgical techniques to control GORD symptoms. Self-management brought about by behavioural change has proven effective in a number of other chronic conditions, and has the potential, along with medical management, to improve symptom control and perhaps, ultimately, reduce PPI use in many patients with persistent GORD symptoms.

A literature review of patient education and selfmanagement programmes in other chronic illnesses was then undertaken, ${ }^{16}$ and the evidence was combined with findings of the qualitative interviews, to develop an education intervention to enhance patient self-management of their symptoms, designed around aspects of chronic disease selfmanagement that are known to be effective. ${ }^{11,17}$

At interview, participants identified that the most commonly occurring influences on their GORD symptoms were diet and stress. Aspects such as smoking, alcohol, exercise, and activity were introduced into the sessions, but because of constraints on time and funding this study focused attention on the self-identified issues. As the intervention was aimed at promoting behavioural change, the National Institute for Health and Clinical Excellence (NICE) principles for designing behavioural-change interventions were used as a framework. ${ }^{18}$

\section{Group intervention stage (stage 2)}

The intervention was designed as a 1.5-hour session per week, for 4 weeks (Table 1).

Of the original 179 responders, 53 had expressed interest in and were recruited to the intervention stage (stage 2 ) of the study. Eleven patients withdrew due to family commitments $(n=3)$, or holiday $(n=2)$, or did not attend $(n=6) ; 42$ patients attended the groups (male $=19$, female $=23$, aged 31-86 years). Groups met on a weekday afternoon or evening. Group sizes varied (group 1, $n=26$; group 2, $n=3$; group 3, $n=8$; group $4, n=5$ ), but membership per group remained consistent throughout the intervention. The attendance rate was $94 \%$, with $6 \%$ of sessions missed due to hospital appointments or illness. No one who commenced withdrew from the intervention.

Diagnoses included reflux/reflux oesophagitis, GORD $(n=16)$, dyspepsia $(n=6)$, hiatus hernia $(n=$ $10)$, Barrett's oesophagus $(n=4)$, and other $(n=6)$. The intervention was delivered in a group format at 


\begin{tabular}{|c|c|c|c|}
\hline Part/week 1 & Part/week 2 & Part/week 3 & Part/week 4 \\
\hline $\begin{array}{l}\text { 1. Consent and } \\
\text { confidentiality }\end{array}$ & $\begin{array}{l}\text { 1. Dealing with diet - what, how, } \\
\text { and when to eat - easy } \\
\text { approaches to relieving symptoms, } \\
\text { using the symptom chart as a guide }\end{array}$ & $\begin{array}{l}\text { 1. Identifying problems: the } \\
\text { patient's self-identified three } \\
\text { biggest problems relating to } \\
\text { reflux }\end{array}$ & $\begin{array}{l}\text { 1. Evaluating action plans and } \\
\text { goals: what to do if the plan } \\
\text { works, what to do if it doesn't }\end{array}$ \\
\hline $\begin{array}{l}\text { 2. Expectations } \\
\text { - setting } \\
\text { realistic goals }\end{array}$ & $\begin{array}{l}\text { 2. Managing stress: learning how } \\
\text { to deal with the stresses that affect } \\
\text { symptoms }\end{array}$ & $\begin{array}{l}\text { 2. Goal setting and action } \\
\text { planning: guiding the patient } \\
\text { to identify what they would like } \\
\text { to achieve, and then devising } \\
\text { a plan of action }\end{array}$ & 2. Talking with the GP \\
\hline $\begin{array}{l}\text { 3. Collecting } \\
\text { baseline data }\end{array}$ & & & $\begin{array}{l}\text { 3. Dealing with breakthrough } \\
\text { symptoms }\end{array}$ \\
\hline $\begin{array}{l}\text { 4. Anatomy and } \\
\text { physiology - } \\
\text { explaining what } \\
\text { happens when } \\
\text { reflux occurs, and } \\
\text { why it happens } \\
\end{array}$ & & & $\begin{array}{l}\text { 4. Maintaining the will to } \\
\text { succeed }\end{array}$ \\
\hline $\begin{array}{l}\text { 5. The symptoms } \\
\text { chart - recording } \\
\text { activity details for } \\
7 \text { days, discerning } \\
\text { patterns between } \\
\text { actions and } \\
\text { symptoms }\end{array}$ & & & 5. Course evaluation \\
\hline
\end{tabular}

venues in the participants' neighbourhood or at their GP surgery, on 4 consecutive weeks in early 2009 by the lead author. The Brief Illness Perception Questionnaire (BIPQ), ${ }^{19}$ the GORD Impact Scale (GIS), ${ }^{20}$ and the Hospital Anxiety and Depression Scale (HADS) ${ }^{21}$ were completed during the first session, and again 3 months after the final session.

\section{RESULTS}

Forty-two patients completed all questionnaires preintervention; three patients were lost to follow-up despite receiving postal reminders, and not all patients completed all questions post-intervention. Thirty-nine sets of data were available for statistical analysis. Data were analysed using SPSS (version 15.0). The Wilcoxon signed ranks test (two-tailed)

Table 2. Overall scores for BIPQ, GIS, and HADS.

\begin{tabular}{|c|c|c|c|c|c|}
\hline & \multicolumn{2}{|c|}{ Before } & \multicolumn{2}{|c|}{ After } & \multirow[b]{2}{*}{$P$-value } \\
\hline & Median & IQR & Median & IQR & \\
\hline BIPQ & 37.50 & $28.25-46.25$ & 28.00 & $28.00-36.00$ & $<0.001$ \\
\hline GIS & 18.00 & $13.00-21.25$ & 14.00 & $12.00-16.00$ & 0.008 \\
\hline $\begin{array}{l}\text { HADS } \\
\text { Anxiety score }\end{array}$ & 6.00 & $4.00-8.25$ & 6.00 & $3.00-9.00$ & 0.361 \\
\hline $\begin{array}{l}\text { HADS } \\
\text { Depression scc }\end{array}$ & 5.00 & $3.00-7.00$ & 4.00 & $2.00-6.00$ & 0.101 \\
\hline
\end{tabular}

$B I P Q=$ Brief IIIness Perception Questionnaire. GIS = GORD Impact Scale. HADS = Hospital Anxeity and Depression Scale. NIQR = interquartile range. was used for non-parametric data (Table 2).

\section{The Brief IIIness Perception Questionnaire (BIPQ)}

There was a significant change $(P<0.001)$ in the overall $\mathrm{BIPQ}$ score following the intervention and in six out of eight domains (Table 3).

No significant change was seen in patients' perceptions of the impact of reflux on their lives before and after the intervention, or in how long they thought their illness would last. The median score in these domains prior to intervention suggests that patients perceived the illness to have only a moderate influence on their lives (median = 5). They also had a very realistic impression of the likely duration of their condition (median $=10$, score of $10=$ forever), a factor that is unlikely to change, irrespective of how well that condition is managed. The remaining domains indicate that following the intervention, patients felt more in control, believed that their treatment can help them, experienced fewer symptoms, were less concerned about their illness, and had a greater understanding of and were less affected emotionally by their reflux than before the intervention.

\section{The GORD Impact Scale (GIS)}

Patients indicated how often in the past week they had experienced the symptoms listed. There was a significant change $(P=0.008)$ in the overall GIS score 
Table 3. Pre- and post-intervention data for the Brief Illness Perception Questionnaire.

\begin{tabular}{|c|c|c|c|c|c|}
\hline & \multicolumn{2}{|c|}{ Before } & \multicolumn{2}{|c|}{ After } & \multirow[b]{2}{*}{$P$-value } \\
\hline & Median & IQR & Median & IQR & \\
\hline Overall score & 37.50 & $28.25-46.25$ & 28.00 & $28.00-36.00$ & $<0.001$ \\
\hline How much does your illness affect you life? & 5.00 & $1.75-6.25$ & 3.00 & $2.00-4.00$ & 0.177 \\
\hline $\begin{array}{l}\text { How long do you think your illnes } \\
\text { will continue? }\end{array}$ & 10.00 & $8.00-10.00$ & 10.00 & $7.75-10.00$ & 0.210 \\
\hline $\begin{array}{l}\text { How much control do you feel you have } \\
\text { over your illness? }\end{array}$ & 6.00 & $4.50-7.50$ & 3.00 & $2.00-4.00$ & $<0.001$ \\
\hline $\begin{array}{l}\text { How much do you think your treatment can } \\
\text { help your illness? }\end{array}$ & 8.00 & $6.00-10.00$ & 2.00 & $1.00-3.00$ & $<0.001$ \\
\hline $\begin{array}{l}\text { How much do you experience symptoms } \\
\text { from your illness? }\end{array}$ & 5.00 & $3.00-7.25$ & 4.00 & $2.00-6.00$ & 0.007 \\
\hline How concerned are you about your illness? & 6.00 & $2.50-8.00$ & 4.00 & $2.00-5.00$ & 0.001 \\
\hline $\begin{array}{l}\text { How well do you feel you understand your } \\
\text { illness? }\end{array}$ & 7.00 & $4.50-8.00$ & 1.00 & $0.00-3.00$ & $<0.001$ \\
\hline How does your illness affect you emotionally? & 4.00 & $1.00-7.00$ & 2.00 & $1.00-4.00$ & $<0.001$ \\
\hline
\end{tabular}

Scores: scale of 0-10, $0=$ no impact and 10 = high impact; lower score indicates improvement. IQR = interquartile range.

Table 4. Pre- and post intervention data for the GORD Impact Scale.

\begin{tabular}{|c|c|c|c|c|c|}
\hline & \multicolumn{2}{|c|}{ Before } & \multicolumn{2}{|c|}{ After } & \multirow[b]{2}{*}{$P$-value } \\
\hline & Median & IQR & Median & IQR & \\
\hline Overall score & 18.00 & $13.00-21.25$ & 14.00 & $12.00-16.00$ & 0.008 \\
\hline Pain in your chest or behind your breastbone? & 2.00 & $1.00-3.00$ & 2.00 & $1.00-2.00$ & 0.09 \\
\hline $\begin{array}{l}\text { Burning sensation in your chest or behind } \\
\text { your breastbone? }\end{array}$ & 2.00 & $1.00-2.00$ & 1.00 & $1.00-2.00$ & 0.001 \\
\hline Regurgitation or acid taste in your mouth? & 2.00 & $2.00-3.00$ & 2.00 & $1.00-2.00$ & 0.002 \\
\hline Pain or burning in your upper stomach? & 2.00 & $2.00-2.75$ & 1.50 & $1.00-2.00$ & 0.007 \\
\hline $\begin{array}{l}\text { Sore throat or hoarseness that is related to } \\
\text { your heartburn or acid reflux? }\end{array}$ & 2.00 & $1.00-3.00$ & 2.00 & $1.00-2.00$ & 0.048 \\
\hline $\begin{array}{l}\text { How often have you had difficulty getting a } \\
\text { good night's sleep because of your symptoms }\end{array}$ & $\begin{array}{l}2.00 \\
\text { ss? }\end{array}$ & $1.00-3.00$ & 2.00 & $1.00-2.00$ & 0.016 \\
\hline $\begin{array}{l}\text { How often have your symptoms prevented } \\
\text { you from eating/drinking the things that } \\
\text { you like? }\end{array}$ & 2.00 & $1.00-3.00$ & 2.00 & $1.00-3.00$ & 0.417 \\
\hline $\begin{array}{l}\text { How often have your symptoms kept you } \\
\text { from being fully productive in your job or } \\
\text { daily activities? }\end{array}$ & 1.00 & $1.00-2.00$ & 1.00 & $1.00-2.00$ & 0.029 \\
\hline $\begin{array}{l}\text { How often do you take additional medication } \\
\text { other than what the doctor has told you to tak }\end{array}$ & $\begin{array}{l}1.00 \\
k e ?\end{array}$ & $1.00-2.00$ & 1.00 & $1.00-2.00$ & 0.398 \\
\hline
\end{tabular}

Scores: never $=1$, sometimes $=2$, often $=3$, daily $=4 . I Q R=$ interquartile range.

following the intervention, and in six out of nine domains (Table 4).

No significant change was seen in patients' reports of pain in the chest or behind the breastbone, in symptoms preventing patients eating or drinking what they wished, or in the use of additional medication to control symptoms. The remaining six domains indicate that following the intervention, patients experienced significantly fewer of the established symptoms associated with reflux disease than they did previously.
The Hospital Anxiety and Depression Scale There was no significant change in the overall anxiety or depression scores (Table 5). The median scores indicate that anxiety and depression among this group was within normal ranges for the general psychiatrically well population.

\section{Number of monthly prescription repeats}

GP database records confirmed that, for the 3 months immediately preceding and following the intervention, patients in the study requested a 
Table 5. Pre- and post-intervention overall scores for the Hospital Anxiety and Depression Scale.

\begin{tabular}{lcccccc} 
& \multicolumn{2}{c}{ Before } & & \multicolumn{2}{c}{ After } & \\
\cline { 2 - 3 } & Median & IQR & & Median & IQR & P-value \\
\hline $\begin{array}{l}\text { HAD Anxiety } \\
\text { Score }\end{array}$ & 6.00 & $4.00-8.25$ & & 6.00 & $3.00-9.00$ & 0.361 \\
\hline $\begin{array}{l}\text { HAD } \\
\text { Depression Score }\end{array}$ & 5.00 & $3.00-7.00$ & & 4.00 & $2.00-6.00$ & 0.101 \\
\hline
\end{tabular}

Minimum score $=0$, maximum score $=21 . I Q R=$ interquartile range.

median of three repeat PPI prescriptions per 3month period. No significant change in repeat prescription requests was seen.

\section{Qualitative data}

Three months after the intervention, patients were given the opportunity to make any free-text comments they wished about their involvement in the programme and experiences with their reflux since then. Content analysis revealed four main categories (Table 6).

\section{DISCUSSION}

\section{Summary of main findings}

The intervention improved patients' perception of their illness at 3 months, and improved their illness experience in many domains. The main improvements were in those domains testing patients' sense of control, perception, and understanding of their condition, and also in symptom severity. Despite a significant change in symptom scores, there was little change in patients' perceptions of how much GORD affected their life. This may be explained by attitudes towards their illness and a determination not to let it impact on their life, despite troubling symptoms. These findings suggest that GORD does affect people's lives and that the intervention may moderate this impact to some extent. The study may, however, have been underpowered to detect other significant differences.

The GIS scores indicate improvements in many of the symptoms associated with GORD. There was no significant difference in patients experiencing pain in the chest or breastbone, but this was an infrequently reported symptom before the intervention, leaving little room for improvement. There was also no improvement in symptoms that prevent patients from eating or drinking the foods that they like, which may reflect the fact that, despite reporting symptoms, patients did not let these interfere with what they wanted to consume anyway. However, qualitative comments from patients suggest a different picture - patients have clearly stated that they have changed eating and drinking habits (content and timing of meals) to successfully manage their symptoms. There was no change in the number of additional medications taken to control symptoms, although the patient group reported minimal use of additional over-the-counter remedies before the intervention. Of the remaining domains, those relating to sore throat, interrupted sleep, and activity show a trend towards significance, suggesting there may be some improvement. All other domains relate

\section{Table 6. Patients' verbatim quotes regarding their progress 3 months after the intervention.}

\begin{tabular}{|c|c|c|c|}
\hline Knowledge and control & Symptoms & Diet & Medications \\
\hline $\begin{array}{l}\text { The course helped me to understand } \\
\text { the condition more }\end{array}$ & $\begin{array}{l}\text { If I have symptoms, it is usually my } \\
\text { fault for drinking champagne, which } \\
\text { is too acidic }\end{array}$ & $\begin{array}{l}\text { I am spacing eating times, not } \\
\text { going too long between meals, } \\
\text { and carrying snacks with me }\end{array}$ & $\begin{array}{l}\text { I did try going without daily } \\
\text { tablet but I can't at the moment, } \\
\text { hope it will happen one day }\end{array}$ \\
\hline $\begin{array}{l}\text { The course helped me to understand } \\
\text { more what causes my symptoms and } \\
\text { how to deal with them }\end{array}$ & There certainly is a slight improvement & $\begin{array}{l}\text { Eating three meals a day, and } \\
\text { eating the right food, has been a } \\
\text { big help }\end{array}$ & $\begin{array}{l}\text { I have almost given up Mepradec }{ }^{\circledast} \\
\text { [omeprazole], but take peptal } \\
\text { liquid most nights }\end{array}$ \\
\hline $\begin{array}{l}\text { The course has made every aspect of } \\
\text { understanding and managing reflux } \\
\text { disease easier }\end{array}$ & $\begin{array}{l}\text { Since the course my symptoms have } \\
\text { got better - less acid, less pain and } \\
\text { less bloated }\end{array}$ & $\begin{array}{l}\text { Taking care what I eat and drink } \\
\text { (decaffeinated tea and coffee now) }\end{array}$ & $\begin{array}{l}\text { I occasionally have to take an } \\
\text { indigestion tablet }\end{array}$ \\
\hline $\begin{array}{l}\text { I feel well - I think the course has } \\
\text { shown me a lot }\end{array}$ & My symptoms are well under control & $\begin{array}{l}\text { I'm avoiding spicy food and hot } \\
\text { drinks, and trying not to overeat }\end{array}$ & $\begin{array}{l}\text { I now take no medication and } \\
\text { experience no symptoms }\end{array}$ \\
\hline $\begin{array}{l}\text { I now understand the difference } \\
\text { between suppressing acid production } \\
\text { and neutralising the acid }\end{array}$ & $\begin{array}{l}\text { I've found it much easier to cope with } \\
\text { my symptoms since completing the } \\
\text { course }\end{array}$ & $\begin{array}{l}\text { Regular meals at normal times, } \\
\text { decaffeinated tea and coffee and } \\
\text { Actimel }^{\circledR} \text { every morning and now } \\
\text { have no symptoms }\end{array}$ & $\begin{array}{l}\text { I still haven't cut down my pill as } \\
\text { I've not yet visited the doctor, } \\
\text { but I will mention it when I see } \\
\text { her }\end{array}$ \\
\hline $\begin{array}{l}\text { The course made me more aware of } \\
\text { my 'bad' eating habits. }\end{array}$ & $\begin{array}{l}\text { My symptoms have been very much } \\
\text { reduced with almost no problems at all }\end{array}$ & $\begin{array}{l}\text { I have learnt what foods trigger my } \\
\text { reflux and try to avoid them }\end{array}$ & \\
\hline $\begin{array}{l}\text { Looking at problems positively and } \\
\text { using self-talk to find ways round them }\end{array}$ & & $\begin{array}{l}\text { I eat earlier and drink little in the } \\
\text { evening, which helps when going } \\
\text { to bed }\end{array}$ & \\
\hline
\end{tabular}


to classic symptoms associated with reflux, and there was improvement in all of these.

The GIS correlates well with quality-of-life scores such as QoLRad, ${ }^{21}$ with a higher score indicating a greater impact on quality of life. There was significant reduction in the median scores and the interquartile range on the GIS, suggesting a corresponding improvement in quality of life at 3 months.

The HADS did not detect any change in anxiety or depression. Since overall scores in both the anxiety and depression scale were within the normal range (0-7) for the population at baseline, there was little opportunity for improvement to be demonstrated.

No change was found in prescription use, although this was not the intention of the study.

\section{Strengths and limitations of the study}

These were self-selected patients who volunteered for the study, and most people approached did not opt in to the intervention. All intervention sessions were delivered by the same person, to ensure parity of experience across each patient group.

The study attempted to collect economic data but responders were found to be reluctant to divulge information, so that the majority of data were void due to incompleteness. This information could provide a useful insight into the ongoing financial impact of GORD on patients' lives. The study lacked a control group, so improvements detected might represent a placebo effect of intervening per se, rather than being attributable to the specific intervention, and the sample sizes were small.

A further large-scale randomised controlled trial would enable confirmation of the findings. The initial follow-up is short at 3 months; however, evidence suggests that if behavioural changes are going to be made, they will be made early and sustained..$^{22}$ The authors plan to test this with further follow-up at 12 months.

\section{Comparison with existing literature}

The only previous trial of an education intervention for GORD was based in Norway, ${ }^{23}$ and found that increased knowledge about GORD had no impact on quality of life or use of health care. Improved quality of life was only seen in patients with education limited to primary school, suggesting that better educated patients are more knowledgeable about GORD and may manage their symptoms more effectively. ${ }^{24}$ Symptom severity or impact of knowledge on disease management were not measured, so it is not known whether that intervention improved the patients' perception and experience of their illness. Contrary to other patient education programme guidance, that study did not appear to include the key components that are known to support patient self-management of illness..$^{17}$ The current study has adopted these proven approaches and enabled patients to make behavioural changes that lead to effective control of the lifestyle issues that influence their symptoms and lead to a corresponding improvement in quality of life.

Generic lifestyle advice for management of GORD does exist but the stage 1 findings ${ }^{15}$ suggest that patient symptom experiences are unique, and that patients may need help to change the behaviours that lead to their lifestyle habits. By incorporating behaviour-change strategies into the education intervention, this study has been able to demonstrate the potential of this approach in managing persistent GORD symptoms. Recent evidence suggests that PPIs may even promote the symptoms they are intended to control. ${ }^{25}$ If this is the case, maintaining patients on, or weaning them off PPIs without giving them a means of managing their symptoms will be very difficult. If, as suggested, the way forward with reflux management is to use more than one approach, ${ }^{9,26}$ an education intervention alongside a carefully managed PPI programme ${ }^{27}$ may have the potential to reduce the long-term use of PPIs and avoid the problem of rebound acid production as well as improving quality of life.

\section{Implications for future research}

These findings suggest that a GORD education programme can have an impact on patient symptom experience. Follow-up is planned at 12 months postintervention, to determine whether changes seen at 3 months are sustained.

A randomised controlled trial with a larger cohort that tests delivery of the intervention in a range of formats is needed in order to develop a programme that is readily available in primary care, economically effective to deliver, and benefits patients.

\section{Funding body}

The study was funded by The Burdett Trust for Nursing, Reference No: 331/390.

\section{Ethics committee}

Ethical approval for the study was granted by Brent Ethics Committee, REC Reference No: 07/H0717/56. Site-specific approvals were granted by Norfolk Research Ethics Committee, SSA Reference Nos: 08/H0310/63; $08 / \mathrm{H0310} / 64$; and $08 / \mathrm{H} 0310 / 65$. Consent was secured from patients at interview, or when attending for the first session of the education programme. Data were stored and handled in accordance with the Data Protection Act (2003). In all representations of the data, patient confidentiality has been maintained.

\section{Competing interests}

Roger Jones has received consultancy and speaking payments from pharmaceutical companies manufacturing drugs for treating gastro-oesophageal reflux disease.

\section{Acknowledgements}

Norfolk R\&D staff, GP practices, and patients. 


\section{Discuss this article}

Contribute and read comments about this article on the Discussion Forum: http://www.rcgp.org.uk/bjgp-discuss

\section{REFERENCES}

1. Dent J, El-Serag H, Wallander M, Johansson S. Epidemiology of gastro-oesophageal reflux disease: a systematic review. Gut 2005; 54(5): 710-717.

2. Shapiro M, Moore A, Fass R. What to do when doubling the dosage isn't enough — refractory gastroesophageal reflux disease - what next? J Respir Dis 2007; 28: 427-434.

3. Health and Social Care Information Centre. Prescription cost analysis for England 2007. London: Government Statistical Service, 2008.

4. Health and Social Care Information Centre. Prescription cost analysis for England 2008. London: Government Statistical Service, 2009.

5. North of England Dyspepsia Guideline Development Group. Dyspepsia: managing dyspepsia in adults in primary care. Report No. 112. Newcastle: University of Newcastle, 2004.

6. Mason J, Hungin A. Review article: gastro-oesophageal reflux disease - the health economic implications. Aliment Pharmacol Ther 2005; 22(suppl 1): 20-31.

7. Raghunath A, O'Morain C, McLoughlin R. Review article: the longterm use of proton-pump inhibitors. Aliment Pharmacol Ther 2005 22(suppl 1): 55-63.

8. Dibley L, Norton C, Jones R. Is there a role for lifestyle education in the management of gastro-oesophageal reflux disease. Eur Gastroenterol Hepatol 2009; 21(11): 1229-1240.

9. Hungin A, Hill C, Raghunath A. Systematic review: frequency and reasons for consultation for gastro-oesophageal reflux disease and dyspepsia. Aliment Pharmacol Ther 2009; 30(4): 331-342.

10. National Institute for Health and Clinical Excellence. Dyspepsia management of dyspepsia in adults in primary care. London: NICE, 2004.

11. Barlow J, Wright C, Sheasby J, et al. Self-management approaches for people with chronic conditions: a review. Patient Educ Couns 2002; 48(2): 177-187.

12. Robinson A, Lee V, Kennedy A, et al. A randomised controlled trial of self-help interventions in patients with a primary care diagnosis of irritable bowel syndrome. Gut 2006; 55(643): 648.

13. Whorwell P. Hypnotherapy for irritable bowel syndrome: the response of colonic and non-colonic symptoms. J Psychosom Res 2008; 64(6): 621-623.

14. Kennedy T, Jones R, Darnley S, et al. Cognitive behaviour therapy in addition to antispasmodic treatment for irritable bowel syndrome in primary care: a randomised controlled trial. BMJ 2005; 331(7514): $435-437$.

15. Dibley L, Norton C, Jones R. Don't eat tomatoes: patient's selfreported experiences of causes of symptoms in gastro-oesophageal reflux disease. Fam Pract 2010; 27(4): 410-417.

16. Dibley L, Norton C, Jones R. Informing a patient education programme for GORD: a literature review. Gastrointest Nurs 2009; 7(5): $28-37$.

17. Lorig K. Patient education: a practical approach. 3rd edn. Thousand Oaks, CA: Sage Publications, Inc, 2001.

18. Abraham C, Kelly M, West R, Michie S. The UK national institute for health and clinical excellence public health guidance on behaviour change: a brief introduction. Psychol Health Med 2009; 14(1): 1-8.

19. Broadbent E, Petrie K, Main J, Weinman J. The Brief Illness Perception Questionnaire. J Psychosom Res 2006; 60(631): 637.

20. Jones R, Coyne K, Wiklund I. The Gastro-Oesophageal Reflux Disease Impact Scale: a patient management tool for primary care. Aliment Pharmacol Ther 2007; 25(12): 1451-1459.

21. Zigmund A, Snaith R. The Hospital Anxiety and Depression Scale. Acta Psychiatr Scand 1983; 67(6): 361-370.

22. Bandura A. Self-efficacy mechanism in human agency. Am Psychol 1982; 37(2): 122-147.

23. Urnes J, Petersen H, Farup P. Patient education in gastro-oesophageal reflux disease. Eur J Gastroenterol Hepatol 2008; 19(12): 1104-1110.

24. Urnes J, Petersen H, Farup P. Disease knowledge after an educational program in patients with GERD - a randomized controlled trial. BMC Health Serv Res 2008; 8: 236

25. Reimer C, Søndergaard B, Hilsted L, Bytzer P. Proton pump inhibito therapy induces acid-related symptoms in healthy volunteers after withdrawal of therapy. Gastroenterology 2009; 137(1): 80-87.

26. Liker H, Ducrotté P, Malfertheiner P. Unmet medical needs among patients with gastroesophageal reflux disease: a foundation for improving management in primary care. Dig Dis 2009; 27(1): 62-67.

27. Van Marrewijk CJ, Mujakovic S, et al. Effect and cost-effectiveness of step-up versus step-down treatment with antacids, $\mathrm{H} 2$-receptor antagonists, and proton pump inhibitors in patients with new onset dyspepsia (DIAMOND study): a primary-care-based randomised controlled trial. Lancet 2009; 373(9659): 215-225. 